\section{(6) OPEN ACCESS}

\title{
The organisation, operational dynamics and structure of female sex work in Pakistan
}

\author{
Faran Emmanuel, ${ }^{1,2}$ Laura H Thompson, ${ }^{1}$ Uzma Athar, ${ }^{2}$ Momina Salim, ${ }^{1}$ Altaf Sonia, ${ }^{2}$ \\ Naeem Akhtar, ${ }^{3}$ James F Blanchard ${ }^{1}$
}

${ }^{1}$ Department of Community Health Sciences, Centre for Global Public Health, University of Manitoba, Winnipeg, Canada

${ }^{2}$ Canada-Pakistan HIV/AIDS Surveillance Project, Islamabad, Pakistan

${ }^{3}$ National AIDS Control

Program, Islamabad, Pakistan

\section{Correspondence to} Dr James F Blanchard, Department of Community Health Sciences, Centre for Global Public Health, University of Manitoba, R070-771 McDermot Ave, Winnipeg, Canada R3E 0T6: james_blanchard @umanitoba.ca

Received 24 January 2013 Revised 4 May 2013 Accepted 11 May 2013 Published Online First 14 June 2013

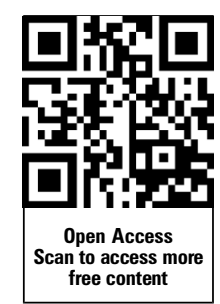

To cite: Emmanuel $F$, Thompson LH, Athar U, et al. Sex Transm Infect 2013;89:ii29-ii33.

\section{ABSTRACT \\ Background Pakistan is known to have large populations of female sex workers (FSWs) with considerable geographic heterogeneity in their characteristics. In this paper, we describe the social organisation and structural patterns of female sex work in different geographic regions of Pakistan. \\ Methods We report geographic and network mapping data collected among FSWs in 15 cities across Pakistan in 2011 as part of the Canada-Pakistan HIVIAIDS Surveillance Project.}

Results A total number of 89178 FSWs were estimated in the target cities for an average of 7.2 FSWs per 1000 adult males. $55 \%$ of the estimated number of FSWs concentrated in Karachi and Lahore. Based on the operations of female sex work, two major typologies of FSWs were identified: establishment-based and nonestablishment-based. FSWs were further subtyped into those operating through brothels, homes, kothikhanas, streets and by cell phone. Cities varied considerably in terms of predominance of different FSW typologies.

Conclusions There is considerable heterogeneity among FSWs in Pakistan, geographically and in terms of operational typology. Understanding the social organisation of sex work and the influence of social-cultural and legal factors in Pakistan is essential for the design of HIV prevention programmes and other services for FSWs.

\section{INTRODUCTION}

Pakistan has a long history of sex work and, although illegal, it is acknowledged to be an 'open secret'. Female sex workers (FSWs) receive money or goods in exchange for sexual services either regularly or occasionally'. ${ }^{1}$ While sex work has long been established world over, the extent, typology and organisation of sex work vary considerably across different countries, cultures and contexts. ${ }^{2}{ }^{3}$ Recently, the social, economic and cultural contexts of sex work have been the subject of much research, often in relation to understanding HIV transmission dynamics. ${ }^{4-6}$ Blanchard and $\mathrm{Aral}^{7}$ describe female sex work as operating within a complex adaptive system with substantial diversity across various cultures. Behaviours and the ways in which sex work is practiced may be responsive to changes in the sociocultural, political, economic and technological contexts. They suggest that sex work in any culture is governed by the macro-level context which influences the size, socioeconomic and demographic characteristics of the FSW and male client populations. The context also influences the organisation of sex work, including features such as the location and venues of sex work (eg, brothels, 'red light' districts), how FSWs and clients connect (eg, by pimps or brokers, through open solicitation, by cell phone), and who controls the work conditions of FSW (eg, individual autonomy, tight controls by madams and pimps). Indeed, FSW and client characteristics and the organisation of sex work influence HIV transmission dynamics. The legal status of sex work in a given region has significant bearings on the way sex work is organised. In settings where legislative frameworks are oriented towards penalising sex workers, as in Pakistan, sexual activities are more likely to be discreet and women may be hesitant to identify themselves as sex workers. ${ }^{8} 9$

It has been well documented that HIV transmission in the context of sex work plays a significant role in the expansion of HIV epidemics in many countries around the world. ${ }^{10} 11$ In countries where HIV transmission is mostly through heterosexual sex, HIV epidemics typically begin among FSWs and their clients before becoming established in the general population (if at all). ${ }^{12}$ In settings with a very low HIV prevalence, monitoring risk behaviours and the prevalence of sexually transmitted infections provides an indication of the potential for HIV transmission. ${ }^{13}$ The trajectory and magnitude of an HIV epidemic are influenced by the prevalence among FSWs and how readily HIV may be transmitted from FSWs to clients, and by the sheer volume of sex workers. ${ }^{14}$ The Asia AIDS Commission estimates that HIV prevention among the 10 million women in Asia who sell sex to at least 75 million men could contribute to a reduction of new HIV infections of up to $75 \% .{ }^{15}$

In 2011, the weighted HIV prevalence was estimated to be $0.63 \%{ }^{16}$ among FSWs in Pakistan, representing a substantial recent increase. It is difficult to accurately measure the size of the sex industry in Pakistan because of its clandestine nature and the wide varieties and geographic distribution of FSWs. However, mapping results suggest a flourishing commercial sex industry, with an estimated 167500 FSWs. $^{17}$ In this paper, we describe the social organisation and structural patterns of female sex work in different geographic regions of Pakistan. This has important implications for HIV transmission dynamics and may be used to inform the development of evidence-based HIV prevention programmes.

\section{METHODS}

The Canada-Pakistan HIV/AIDS Surveillance Project conducted a fourth round of data collection in 2011 as part of its second generation surveillance system. Mapping was conducted to locate, enumerate, and characterise populations of injection drug users and male, hijra (transgender) and FSWs, and integrated 
biological and behavioural surveillance took place among a sample of each key population. Sex work was defined as the provision of sex to a man in exchange for money or other financial benefits, and the study was restricted to FSWs 15 years of age and older. This paper presents results of FSW population mapping which was conducted in 15 cities across the four provinces of Pakistan; including six cities in Punjab, six in Sindh, two in Khyber Pukhtoonkhwa and one city in Baluchistan.

Mapping was conducted using parallel geographic and network mapping approaches. The field operations of the geographic approach comprised of two major phases, referred to as 'levels'. In Level 1, secondary key informants (eg, taxi/rickshaw drivers, shopkeepers, public call office operators, hawkers) were interviewed about the geographic locations ('hot spots') where FSWs congregate and solicit clients. This information was validated in Level 2 by interviewing primary key informants (FSWs, pimps and madams). Madams are women who operate brothels. At each hot spot, the field team recruited a group of FSW community members with the help of social mobilisers (FSW community leaders) to validate information collected in Level 1 and to collect more accurate information about the hot spot. Social mobilisers were FSW community members who have detailed knowledge of the operations and spread of sex work in various areas throughout the city and who consented to participate in the study. They were introduced to study staff by secondary key informants. In addition to population size estimates, information about group and operational dynamics and FSW typologies were collected by asking FSWs, pimps and madams about where and how they solicit their clients and where they engage in sexual activity. Network operators control and protect the operation of home-based, brothel-based and kothikhana-based FSWs by bringing them clientele and providing space for sexual activity in exchange for a proportion of the sex workers' income. To supplement geographic mapping data, network mapping was conducted in an attempt to obtain information about FSWs who may not frequent commonly known hot spots. This process began by interviewing network operators to obtain information about FSW and pimp/madam members of their network and their locations. Network operators introduced willing members of their contact networks to the study team and this snowball approach continued until no new locations and networks were identified.

All data were field edited and data were entered using Microsoft Access. FSW population sizes were estimated for the local neighbourhood (zone) and city levels using estimated ranges for each hot spot, with adjustments for duplications.

\section{RESULTS}

A total of 11190 interviews were conducted in the target cities during Level 1 mapping, followed by more than 4000 interviews conducted as part of Level 2 to gather information about the hot spots where FSWs congregate. In addition to these interviews, 2127 network operators and pimps were interviewed about the characteristics of networks of sex work.

Six different FSW typology categories were identified (figure 1). Home-based FSWs live in their homes with families, and rely mostly on network operators to seek clients. There are categories of home-based FSWs: those for whom the family is unaware and sex work takes place elsewhere, and those for whom the family is aware and sex work takes place in the home. Kothikhana-based FSWs live and entertain clients in buildings that are generally small

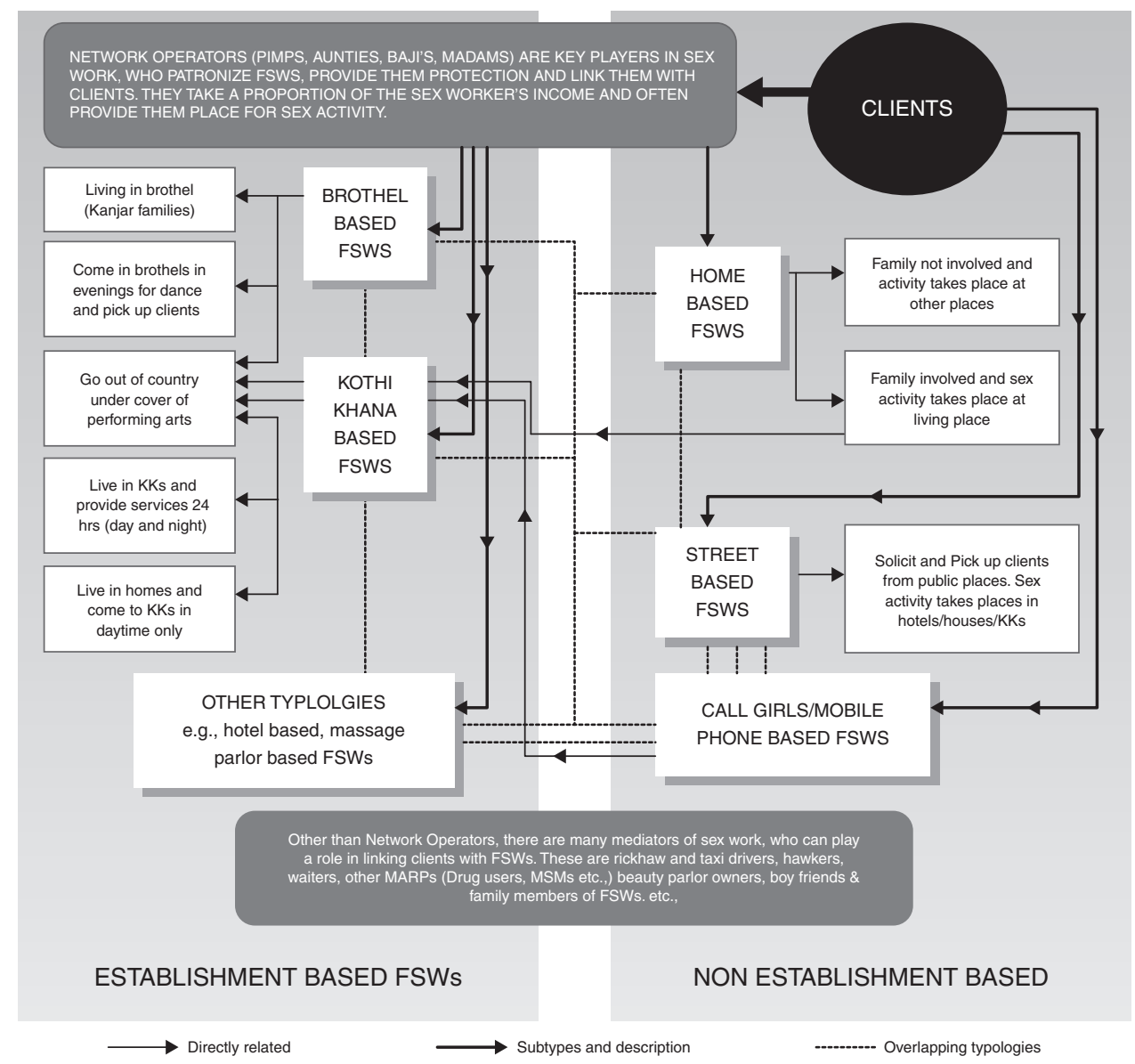

Figure 1 Operational model of sex work in Pakistan. FSW, female sex worker. 
premises in residential areas rented by a network operator. Sometimes FSWs who do not live in kothikhanas perform sex work in these venues. Brothel-based sex work is the oldest variant of female sex work in Pakistan when the sex industry was mainly housed in brothels located in designated red light areas and provided sexual services to clients under cover of singing and dancing. Street-based sex workers tend to work alone in nonspecific locations and solicit clients at various 'pick up points' in public places such as streets, market places and bus stops. They may perform sex work in hotels, houses or kothikhanas. An emerging mechanism which FSWs use to contact clients is through cell phones. A few other typologies of FSWs included hotel-based FSWs, massage parlour-based FSWs and beggars.

FSWs in Pakistan can be broadly classified as 'establishmentbased' and 'non-establishment-based'. Establishment-based sex workers refer to FSWs who are connected to a formal structure whereby network operators facilitate commercial sex transactions, usually at specific locations such as brothels, kothikhanas and hotels. Sex workers within this category operate within this closed network of network operators and clients and do not usually find clients independently. As illustrated in figure 1, network operators such as pimps, madams, and sometimes other mediators such as taxi drivers and waiters play a significant role in linking FSWs to clients in exchange for a proportion of the sex workers' income. Network operators may also provide protection to sex workers and places for sexual activity. FSWs based in brothels, kothikhanas, their homes, and other venues such as hotels and massage parlours often rely on network operators to connect with clients.

In contrast, non-establishment-based FSWs usually work alone and solicit clients directly in public places such as on the street and in market areas. Individuals such as cab drivers, hawkers and even family members may act as mediators of these commercial sexual interactions. In particular, cell phone-based and street-based sex workers often connect with clients directly. Home-based sex workers are a variant within this typology, and largely depend on network operators for their clientele and operation. While these high-level classifications encompass a broad spectrum of sex work, there is often considerable overlap between categories, and individual FSWs often do not clearly fit into one category or move between these categories periodically.
We estimated a total number of 89178 FSWs in the 15 cities where mapping was conducted, with considerable geographic heterogeneity and $55 \%$ of the estimated number of FSWs concentrated in Karachi and Lahore (table 1). Nawabshah had the highest estimated number of FSWs per 1000 adult males (14.2) and Peshawar had the smallest ratio with an estimated 3.4 FSWs per 1000 adult males. Cities varied considerably in terms of predominance of different FSW typologies. The largest typology identified was home-based FSWs estimated at 41313 and representing almost half of the total number of sex workers in Pakistan. A large proportion of FSWs are home-based in DG Khan $(66.5 \%)$ and Larkana (62.9\%), while only $20.4 \%$ of FSWs in Haripur are home-based. 'Kothikhana-based FSWs' are the next largest category, forming $23.5 \%$ of the total volume of FSW operating in Pakistan. In Quetta, a large proportion of FSWs are kothikhana-based (37\%) compared with Larkana (3.7\%). About 18275 (21\%) of the FSW population in Pakistan are street-based, composing a large proportion of the FSW population in Sargodha (41.6\%) and a small proportion in Larkana (1.3\%) and DG Khan (3.8\%). Brothel-based sex work accounts for only $1.4 \%$ of the sex worker population in Pakistan, although brothel-based sex workers compose a relatively large proportion of the FSW population in Larkana (11.2\%). A relatively small number of sex workers (5.3\%) have also been identified as cell phone-based, and this group is well represented in Peshawar, composing $30.5 \%$ of the FSW population there.

A total of 12162 network operators were estimated in the cities included, ranging from 128 in Karachi to 3623 in Sukkur and 3359 in Lahore (table 2). On average, there were 5.2 home-based or kothikhana-based FSWs per network operator (3.5 home-based FSWs and 1.7 kothikhana-based FSWs) ranging from 3.1 in Mirpurkhas to 7.9 in Sukkur. On average, there are 4.5 kothikhana-based FSWs per kothikhana ranging from 2 per kothikhana in Larkana to 14.1 per kothikhana in Sukkur.

\section{DISCUSSION}

Pakistan has large and diverse populations of FSWs with substantial geographic heterogeneity. In particular, Karachi and Lahore have very large FSW populations. The main financial

Table 1 Estimated numbers of female sex workers (FSWs) by typology in four cities in Pakistan in 2011.

\begin{tabular}{|c|c|c|c|c|c|c|c|c|c|c|c|c|c|c|c|}
\hline \multirow[b]{2}{*}{ Province } & \multirow[b]{2}{*}{ City } & \multicolumn{2}{|c|}{ BBFSWs } & \multicolumn{2}{|l|}{ SBFSWs } & \multicolumn{2}{|c|}{ HBFSWs } & \multicolumn{2}{|c|}{ KKFSWs } & \multicolumn{2}{|c|}{ CBFSWs } & \multicolumn{2}{|c|}{ Other FSWs } & \multirow[b]{2}{*}{ Total FSWs } & \multirow{2}{*}{$\begin{array}{l}\text { FSWs/1000 } \\
\text { adult males }\end{array}$} \\
\hline & & \# & $\%$ & \# & $\%$ & \# & $\%$ & \# & $\%$ & \# & $\%$ & \# & $\%$ & & \\
\hline \multirow[t]{6}{*}{ Punjab } & DG Khan & 0 & 0.0 & 53 & 3.8 & 939 & 66.5 & 387 & 27.4 & 34 & 2.4 & 0 & 0.0 & 1413 & 13.3 \\
\hline & Faisalabad & 0 & 0.0 & 882 & 18.2 & 2887 & 59.6 & 878 & 18.1 & 59 & 1.2 & 140 & 2.9 & 4846 & 5 \\
\hline & Lahore & 350 & 1.5 & 4597 & 19.3 & 12683 & 53.4 & 5303 & 22.3 & 579 & 2.4 & 254 & 1.1 & 23766 & 11.5 \\
\hline & Multan & 148 & 2.8 & 448 & 8.4 & 2754 & 51.9 & 1449 & 27.3 & 171 & 3.2 & 338 & 6.4 & 5308 & 8 \\
\hline & Rawalpindi & 0 & 0.0 & 748 & 20.6 & 1955 & 53.8 & 851 & 23.4 & 0 & 0.0 & 81 & 2.2 & 3635 & 3.4 \\
\hline & Sargodha & 80 & 2.1 & 1621 & 41.6 & 1022 & 26.2 & 990 & 25.4 & 82 & 2.1 & 103 & 2.6 & 3898 & 12.5 \\
\hline \multirow[t]{6}{*}{ Sind } & Hyderabad & 220 & 4.8 & 887 & 19.4 & 1707 & 37.4 & 978 & 21.4 & 601 & 13.2 & 173 & 3.8 & 4566 & 8.5 \\
\hline & Karachi & 175 & 0.7 & 6298 & 24.8 & 10915 & 43.0 & 7138 & 28.1 & 763 & 3.0 & 110 & 0.4 & 25399 & 5.5 \\
\hline & Larkana & 125 & 11.2 & 15 & 1.3 & 701 & 62.9 & 41 & 3.7 & 232 & 20.8 & 0 & 0.0 & 1114 & 8.2 \\
\hline & Mirpurkhas & 0 & 0.0 & 222 & 25.1 & 356 & 40.3 & 183 & 20.7 & 20 & 2.3 & 103 & 11.7 & 884 & 8.5 \\
\hline & Nawabshah & 170 & 8.5 & 525 & 26.1 & 839 & 41.7 & 146 & 7.3 & 331 & 16.5 & 0 & 0.0 & 2011 & 14.2 \\
\hline & Sukkur & 0 & 0.0 & 350 & 15.1 & 1326 & 57.2 & 260 & 11.2 & 308 & 13.3 & 73 & 3.2 & 2317 & 10.5 \\
\hline \multirow[t]{2}{*}{ KPK } & Haripur & 0 & 0.0 & 346 & 11.6 & 611 & 20.4 & 230 & 7.7 & 521 & 17.4 & 1286 & 43.0 & 2994 & 11.9 \\
\hline & Peshawar & 0 & 0.0 & 529 & 15.9 & 1032 & 31.1 & 722 & 21.8 & 1013 & 30.5 & 21 & 0.6 & 3317 & 4.2 \\
\hline Balochistan & Quetta & 0 & 0.0 & 754 & 20.3 & 1586 & 42.7 & 1370 & 36.9 & 0 & 0.0 & 0 & 0.0 & 3710 & 10.7 \\
\hline Total & & 1268 & 1.4 & 18275 & 20.5 & 41313 & 46.3 & 20926 & 23.5 & 4714 & 5.3 & 2682 & 3.0 & 89178 & 7.2 \\
\hline
\end{tabular}

BBFSWs, brothel-based FSWs; CBFSW, cell phone-based FSWs; HBFSWs, home-based FSWs; KKFSW, kothikhana-based FSWs; KPK, Khyber Pakhtunkhwa; SBFSWs, street-based sex workers. 
Table 2 Number of network operators and FSWs working in networks in Pakistan in 2011

\begin{tabular}{|c|c|c|c|c|c|c|c|}
\hline \multirow[b]{2}{*}{ Province } & \multirow[b]{2}{*}{ City } & \multirow[b]{2}{*}{ \# Network operators } & \multicolumn{3}{|c|}{$\begin{array}{l}\text { Average \# FSWs per network } \\
\text { operator }\end{array}$} & \multirow{2}{*}{$\begin{array}{l}\text { Average \# kothikhanas } \\
\text { listed by each network operator }\end{array}$} & \multirow{2}{*}{$\begin{array}{l}\text { Average \# KKFSWs } \\
\text { per kothikhana }\end{array}$} \\
\hline & & & HBFSW & KKFSW & Total & & \\
\hline \multirow[t]{6}{*}{ Punjab } & DG Khan & 290 & 3.2 & 1.3 & 4.6 & 1.9 & 3.5 \\
\hline & Faisalabad & 1013 & 2.8 & 1 & 3.8 & 2.1 & 3.2 \\
\hline & Lahore & 3359 & 3.8 & 1.6 & 5.4 & 11.9 & 2.9 \\
\hline & Multan & 789 & 3.5 & 1.8 & 5.3 & 4.4 & 4.8 \\
\hline & Rawalpindi & 674 & 2.9 & 1.3 & 4.2 & 4.6 & 3.2 \\
\hline & Sargodha & 272 & 3.8 & 3.6 & 7.4 & 6.7 & 3.6 \\
\hline \multirow[t]{6}{*}{ Sind } & Hyderabad & 333 & 3.8 & 2.2 & 5.9 & 7.2 & 3.9 \\
\hline & Karachi & 128 & 3 & 2 & 5 & 4.3 & 3.2 \\
\hline & Larkana & 521 & 4.7 & 0.3 & 5 & 4.4 & 2 \\
\hline & Mirpurkhas & 202 & 2 & 1 & 3.1 & 3.5 & 2.9 \\
\hline & Nawabshah & 452 & 4.6 & 0.8 & 5.4 & 4.3 & 6.5 \\
\hline & Sukkur & 3623 & 6.6 & 1.3 & 7.9 & 7.1 & 14.1 \\
\hline \multirow[t]{2}{*}{ KPK } & Haripur & 148 & 4.8 & 1.8 & 6.6 & 3.1 & 4.6 \\
\hline & Peshawar & 175 & 3.1 & 2.2 & 5.3 & 1.3 & 3.4 \\
\hline Balochistan & Quetta & 183 & 3 & 2.6 & 5.7 & 5.9 & 6.3 \\
\hline Total & & 12162 & 3.5 & 1.7 & 5.2 & 4.8 & 4.5 \\
\hline
\end{tabular}

FSWs, female sex workers; HBFSW, home-based FSW; KKFSW, kothikhana-based FSW; KPK, Khyber Pakhtunkhwa.

centre of Pakistan, Karachi is the most populous city of Pakistan and is home to the largest number of injection drug users and male, hijra and FSWs. ${ }^{18}$ Lahore has a long history of brothels and FSWs continue to be the predominant key population in Lahore. ${ }^{18}$ However, when comparing the number of FSWs with the adult male population, the less populous city of Nawabshah has the largest population of FSWs relative to men.

The local socio-cultural and legal context influences the size of FSW populations, their characteristics and their operational typologies. Commercial sex work was originally prohibited by the Pakistan Penal Code of 1860 under colonial rule and later by the Hudood Ordinance, a compilation of Islamic laws enacted in 1979, which incorporate punishments of lashings and death by stoning. ${ }^{19} 20$ The laws are often used as a threat by police and law enforcement agencies to make money rather than to control commercial sex work. Anecdotal evidence gathered through interviews with brothel and kothikhana owners suggested that nearly all pay a share of their income to the local police. $^{21}$ Less conservative cities such as Lahore and Karachi continue to have substantial numbers of street-based sex work, but in contrast networks operators play a much larger role in the more conservative cities of Quetta and Peshawar, where there is a greater proportion of home-based and kothikhanabased FSWs and an absence of brothels.

The configuration of female sex work has changed considerably in the past few years. ${ }^{22}$ A shift away from street-based sex work has been noted, while home-based sex work has increased in the past 4 years. ${ }^{22}$ Generally, the sex industry in Pakistan is moving out of traditional sites and red light areas and is becoming dispersed throughout cities and moving into suburbs and smaller towns. ${ }^{22}$ Recent evidence demonstrates an increase in the number of hot spots, but a reduction in the number of FSWs who congregate at each spot. ${ }^{21} 23$ On average, the proportion of brothel-based sex work estimated in our 2011 study, approximately $1 \%$, is lower than the figure reported in $2007,2.2 \%{ }^{22}$

In smaller cities, sex work is extremely hidden and most FSWs connect with clients through network operators, while in larger less conservative cities, a substantial number of FSWs still operate independently through particular street locations known to clients. This, however, does not preclude the role of network operators and pimps in larger cities as well who do have an important role in connecting sex workers and clients. The proportion of sex workers estimated to be primarily using cell phones to reach clients, 5\%, represents an increase from $1.8 \%$ reported in $2007 .^{22}$ This may be a result of sex work becoming more 'hidden' due to the increasing presence of the Taliban, with some street-based sex workers beginning to connect with clients through cell phones and arranging to be picked up at specific street locations; anecdotal data from fieldwork support this hypothesis.

Knowledge about the typologies and operational dynamics of female sex work, in concert with local transmission dynamics, may be used to design programmes which provide FSWs with the services they need in a configuration which is accessible and effective. Mapping data can be used to determine the optimal distribution and reach of HIV prevention services by identifying and describing locations where sex work is conducted at high densities, or 'hot spots' and is therefore essential for HIV prevention programme design. As Pakistan becomes more socially conservative and female sex work increasingly operates through networks and cell phones, FSWs may be becoming more isolated and vulnerable and also more difficult for HIV prevention programmes to reach. As in other regions of the world, female sex work exhibits considerable heterogeneity in Pakistan, geographically and in terms of operational typology. ${ }^{24}$

The mapping methodology relies on the identification of spots frequented by sex workers by secondary key informants. It is possible that some spots are missed and some 'hidden' typologies such as home-based sex work typologies may be underestimated. The mapping data presented in this paper are estimates specific to the cities in which data collection took place and should not be extrapolated to other cities in Pakistan. Moreover, it does not describe the practice of sex work in rural areas. Given the responsiveness of FSW behavioural and operational patterns to local contexts, the data used to design programmes which will be locally implemented should be obtained in those specific contexts.

Despite these limitations, this research has helped us understand the changing trends of sex work in Pakistan. Our findings underscore the extensive spread of sex work in Pakistan, which is evolving and dispersing out of the traditional locales. With the large volume of FSWs in Pakistan and evidence of low rates of condom use, ${ }^{16}$ there is a great potential for HIV transmission 
and a concomitant rapid increase in HIV prevalence among FSWs and their clients. Understanding the social organisation of sex work and the influence of social-cultural and legal factors in Pakistan is essential for the design of HIV prevention programmes and other services for FSWs.

\section{Key messages}

- Pakistan is known to have large populations of female sex workers (FSWs) with considerable geographic heterogeneity in their characteristics.

- The fifteen cities included in this study were estimated to have a total of 89178 FSWs, 55\% concentrated in Karachi and Lahore.

- Cities varied considerably in terms of predominance of different FSW typologies, including those operating through brothels, homes, kothikhanas, streets and cell phones.

- Understanding the social organisation of sex work and the social and political context is essential for the design of HIV prevention programmes for FSWs in Pakistan.

\section{Handling editor Jackie Cassell.}

Acknowledgements We thank the Canada-Pakistan HIVIAIDS Surveillance Project (HASP) team for their efforts in mapping, data collection, specimen collection, data entry and knowledge translation. We also thank study participants for their time and willingness to answer sensitive questions. We thank Dr Tahira Reza (HASP) for her assistance with data management.

Contributors FE conducted the surveillance project that generated the mapping data presented in this paper. FE wrote the first draft of this manuscript and contributed to interpretation of results and manuscript revisions. LHT and MS contributed to analysis, manuscript writing and interpretation of results. UA, MS, AS, and NA contributed to the surveillance project and data collection, and critically reviewed the manuscript. JFB provided direction for the development of this manuscript, critically reviewed the manuscript and led the development of special supplement strategy.

Funding The Canada-Pakistan HIVIAIDS Surveillance Projected was funded by the Canadian International Development Agency (contract no. CIDA PK 30849).

\section{Competing interests None.}

Patient consent Obtained.

Ethics approval This study was approved by the institutional ethical review boards of HOPE International in Pakistan and the Public Health Agency of Canada.

Provenance and peer review Commissioned; externally peer reviewed.

Open Access This is an Open Access article distributed in accordance with the Creative Commons Attribution Non Commercial (CC BY-NC 3.0) license, which permits others to distribute, remix, adapt, build upon this work non-commercially, and license their derivative works on different terms, provided the original work is properly cited and the use is non-commercial. See: http://creativecommons.org/ licenses/by-nc/3.0/

\section{REFERENCES}

1 UNAIDS. Sex work and HIVIAIDS. UNAIDS Technical Update. UNAIDS Best Practice Collection. UNIADS Geneva. Switzerland. June 2002

2 Harcourt C, Donovan B. The many faces of sex work. Sex Transm Infect 2005;81:201-6

3 Vandepitte J, Lyerla R, Dallabetta G, et al. Estimates of the number of female sex workers in different regions of the world. Sex Transm Infect 2006;82(Suppl III): iii18-25.

4 Blanchard JF, Moses S. Female sex workers and their clients in the epidemiology and control of sexually transmitted diseases. In: Holmes KK, ed. Sexually transmitted diseases. 4th edn. New York: McGraw-Hill, 2007

5 Wasserheit JN, Aral SO. The dynamic topology of sexually transmitted disease epidemics: implications for prevention strategies. J Infect Dis 1996;174(Suppl 2): s201e13.

6 Rothenberg R. STD transmission dynamics: some current complexities. 2002 Thomas Parran Award Lecture. Sex Transm Dis 2003:30:478e82.

7 Blanchard JF, Aral S. Emergent properties and structural patterns in sexually transmitted infection and HIV research. Sex Transm Infect 2010;86:iii4-9.

8 Csetea J, Dubeb S. An inappropriate tool: criminal law and HIV in Asia. AIDS 2010;24(Suppl 3):S80-5.

9 Hasnain M. Cultural approach to HIVIAIDS harm reduction in Muslim countries. Commentary. Harm Reduction J 2005:2:23.

10 Jha P, Nagelkereke NJD, Ngugi EN, et al. Reducing HIV transmission in developing countries. Science 2001;292:224-5.

11 Day $\mathrm{S}$, Ward $\mathrm{H}$. Sex workers and the control of sexually transmitted disease. Genitourin Med 1997;73:161-8.

12 Ghys $P$, Jenkins $C$, Pisani E. HIV surveillance among female sex workers. AIDS 2001;15(Suppl 3):S33-40.

13 SGS Guidelines UNAIDS.

14 Talbott JR. Size matters: the number of prostitutes and the global HIVIAIDS pandemic. PLOS ONE 2007:2:e543.

15 Commission on AIDS in Asia. Redefining AIDS in Asia: crafting an effective response. New Delhi: Oxford University Press, 2008.

16 Mishra S, Thompson LH, Sonia A, et al. Sexual behavior, structural vulnerabilities, and HIV prevalence among female sex workers in Pakistan. Sex Transm Infect 2013;89:ii34-42.

17 Emmanuel F, Blanchard J, Zaheer $\mathrm{H}$, et al. The HASP team. The HIVIAIDS Surveillance Project mapping approach: an innovative approach for mapping and size estimation for groups at a higher risk of HIV in Pakistan. AIDS 2010;24: 577-84.

18 National AIDS Control Program. HIV Second Generation Surveillance in Pakistan Mapping Report 2011. Round Four Mapping Report. http://www.nacp.gov.pk/ surveillance_and_research/ (accessed 17 Dec 2012).

19 The Offence of Zina (Enforcement Of Hudood) Ordinance, 1979. Ordinance No. VII of 1979. Pakistan. http://www.pakistani.org/pakistan/legislation/zia_po_1979/ ord7_1979.htm

20 Faroog MO. Rape and Hudood Ordinance: Perversions of Justice in the Name of Islam. Islamicity. 2006. http://www.globalwebpost.com/farooqm/writings/gender/ rape figh.html (accessed 5 Dec 2006).

21 UNFPA 2008. Sex Work and HIV in Pakistan; A Situation and Response Analysis. UNFPA Pakistan

22 National AIDS Control Program. HIV Second Generation Surveillance in Pakistan 2007. Round Two Report. http://www.nacp.gov.pk/surveillance and research/ (accessed 17 Dec 2012).

23 National AIDS Control Program. HIV Second Generation Surveillance in Pakistan 2005. Round One Report. http://www.nacp.gov.pk/surveillance_and_research/ (accessed 17 Dec 2012)

24 Blanchard JF, Khan A, Bokhari A. Variations in the population size, distribution and client volume among female sex workers in seven cities of Pakistan. Sex Transm Infect 2008:84(Suppl 2):ii24e7. 